\title{
DÜBLIN
}

Technological University Dublin

ARROW@TU Dublin

2015-5

\section{Valorization of Fish By-Products: Rheological, Textural and Microstructural Properties of Mackerel Skin Gelatins}

\author{
Zied Khiari \\ University of Alberta, khiari@ualberta.ca \\ Daniel Rico \\ Technological University Dublin, daniel.rico@tudublin.ie \\ Ana Belen Martin-Diana \\ Technological University Dublin, anabelen.martindiana@tudublin.ie
}

See next page for additional authors

Follow this and additional works at: https://arrow.tudublin.ie/schfsehart

Part of the Food Science Commons

\section{Recommended Citation}

Khiari, Z., Rico, D., Martin-Diana, A. and Barry-Ryan, C. Valorization of fish by-products: rheological, textural and microstructural properties of mackerel skin gelatins. Journal of material cycles and waste management. 10.1007/s10163-015-0399-2

This Article is brought to you for free and open access by the School of Food Science and Environmental Health at ARROW@TU Dublin. It has been accepted for inclusion in Articles by an authorized administrator of ARROW@TU Dublin. For more information, please contact arrow.admin@tudublin.ie, aisling.coyne@tudublin.ie, gerard.connolly@tudublin.ie.

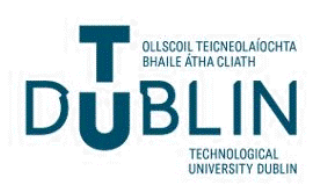


Authors

Zied Khiari, Daniel Rico, Ana Belen Martin-Diana, and Catherine Barry-Ryan

This article is available at ARROW@TU Dublin: https://arrow.tudublin.ie/schfsehart/203 
Valorization of fish by-products: rheological, textural and microstructural properties of mackerel skin gelatins

Zied Khiari*, Daniel Rico, Ana Belen Martin-Diana and Catherine Barry-Ryan.

School of Food Science and Environmental Health, Dublin Institute of Technology (DIT), Cathal Brugha Street, Dublin 1, Ireland.

* Corresponding author/Present address: Zied Khiari, Department of Agricultural Food \& Nutritional Science (AFNS). 4-10, Agriculture/Forestry Centre.

University of Alberta. Edmonton, AB, Canada T6G 2P5.

Tel: +1 7804924321 .

Email: khiari@ualberta.ca 


\begin{abstract}
The fish processing industry generates significant amounts of waste which is usually discarded. The present study investigated the recovery of gelatins from Atlantic mackerel (Scomber scombrus) skins after pre-treatment with different environmentally-friendly organic acids (acetic, citric, lactic, tartaric or malic acid). The chemical composition, the rheological and the textural properties as well as the microstructural characteristics of the extracted gelatins were analysed and compared to commercial bovine hide gelatin. Although the organic acid used in the pretreatment step did not affect the extraction yield and the chemical composition of the prepared gelatins, differences were observed in terms of rheology and texture. The highest gel strength $(\mathrm{p}<0.05)$ was observed with gelatins extracted after pretreatment with acetic, citric and malic acids $(71-80 \mathrm{~g})$. From an industrial point of view, gelatin can be extracted using any of these organic acids with similar yield. However, in order to obtain better rheological and textural properties the use of acetic, citric or malic acid in the pre-treatment step is recommended.
\end{abstract}

Key words: mackerel skin, gelatin, organic acid, texture, rheology, microstructure. 


\section{Introduction}

Collagen is the most abundant protein in the animal body which represents the major fraction of tendons, skin, bones and connective tissues [1]. The thermal denaturation of collagen produces gelatin, a protein ingredient widely used in the cosmetics, pharmaceutical and food industries, due to its important physical functionality. In the food sector, gelatin is known to improve the elasticity, consistency and stability of the food formulations [2]. Pigskin and cattle bone and hide are generally the main source of commercial gelatins. Fish gelatin gained interest following the outbreak of bovine spongiform encephalopathy (BSE) [3]. In spite of being considered superior to fish gelatins [4], in terms of functional properties, mammalian gelatins may give rise to some dietary concerns. For some cultural, religious and ethnic reasons pig gelatin is prohibited for use [5]. The increasing demand for halal and kosher foods makes fish gelatin suitable as an alternative to mammalian gelatins.

Fisheries and the fish processing industries are important economic sectors in the world with an estimated global production (both farmed and wild fish catch) of around 148 million tons in 2010 [6]. The fish processing industry generates significant amounts of waste. In general, only the fillets are retained [7] and the bulk of the product consisting of head, guts and frame is usually discarded. This waste represents a potential source for gelatin [8].

The production method significantly affects the physicochemical properties of the gelatin [9]. The industrial process of gelatin manufacture involves either an acid or an alkaline pre-treatment, to break the collagen cross-links, followed by solubilisation of collagen fibers by a thermal treatment. For fish materials, acid pre-treatment is usually required to partially cleave the non-covalent bonds in the fish collagen fibers 
since high levels of hydrogen ions increase the penetration of water around the collagen fibers [9]. Both mineral and organic acids can be used in the extraction of fish gelatins. However, the use of organic acids in the pre-treatment step is preferable.

The main objective of the present work was to extract gelatins from mackerel skins using different organic acids (acetic, citric, lactic, malic or tartaric acids) and to evaluate their effects on the rheological, textural and microstructural properties of the extracted ingredients.

\section{Materials and methods}

\subsection{Materials}

Atlantic mackerel (Scomber scombrus) were kindly provided by Bord Iascaigh Mhara (BIM, Dublin, Ireland). Mackerel skins were manually removed from the fillet using a knife and cut into small squares $\left(4 \mathrm{~cm}^{2}\right)$ using a scissor. The processed skins were divided into batches and kept in the freezer at $-20^{\circ} \mathrm{C}$ until use in less than a month.

\subsection{Characterisation of mackerel skin}

\subsubsection{Proximate analysis}

The chemical composition of mackerel skin was carried out according to the procedures of the Association of Official Analytical Chemists [10]. Moisture and ash contents were determined according to the methods number 927.05 and 942.05, respectively [10]. Crude protein was determined by Kjeldahl method following the method number 984.13 [10] and using a nitrogen conversion factor of 6.25. Lipid content was determined according to the Bligh and Dyer method [11]. 


\subsubsection{Hydroxyproline content}

The hydroxyproline content of mackerel skin was determined according to the method of Edwards and O'Brien [12] and the collagen content was estimated using a conversion factor of 7.14.

\subsection{Extraction of gelatin}

Gelatin extraction was carried out according to the method described by Khiari et al. [13]. Briefly, mackerel skins $(\sim 1.5 \mathrm{~kg})$ were treated with $0.1 \mathrm{~N} \mathrm{NaOH}$ (for 30 min at $4{ }^{\circ} \mathrm{C}$, repeated 3 times), followed by an acid treatment. In this study, different organic acids (acetic, citric, lactic, malic or tartaric acid) were used separately at different concentrations (25, 50 or $100 \mathrm{mM}$ ). The acid treatment was carried out for 4 h at $4{ }^{\circ} \mathrm{C}$. At the end of this step, mackerel skins were washed with distilled water to remove the acid. Gelatin was extracted at $45{ }^{\circ} \mathrm{C}$ for $18 \mathrm{~h}$ with distilled water then filtered through Whatman No. 4 filter paper (Whatman, Maidenstone, England). Gelatin was deionized using Rexyn ${ }^{\mathrm{TM}} \mathrm{I}-300(\mathrm{H}-\mathrm{OH})$ beads, then concentrated by evaporation at $45{ }^{\circ} \mathrm{C}$ under vacuum to prevent possible thermal degradation (Büchi UK Ltd., Oldham, UK), and finally freeze dried (Labconco Corporation, Kansas City, MO, USA). All pre-treatment and extraction procedures were done under continuous agitation at $150 \mathrm{rpm}$ and in a raw material/solvent ratio of 1/3 (w/v).

\subsection{Gelatin extraction yield}

Gelatin extraction yield was calculated on a dry basis according to Du et al. [14] as the amount of gelatin with respect to the amount of collagen in the raw material using the following formula: 
Gelatin extraction yield $(\%)=\frac{\text { Dry weight of extracted gelatin }(g)}{\text { Dryweight of collagen in mackerel skin }(g)}$

\subsection{Characterisation of gelatins}

\subsubsection{Proximate analysis of gelatin}

The chemical composition of gelatins was carried out according to the methods $[10,11]$ previously described in Section 2.2.1. The protein content of gelatin was calculated using a nitrogen conversion factor of 5.4 [15].

\subsubsection{Protein profile of gelatins}

The electrophoresis procedure was carried out according to Khiari et al. [16]. Briefly, $10 \mu \mathrm{L}$ of gelatin samples $(2 \mathrm{mg} / \mathrm{mL})$ and molecular weight markers were loaded onto SDS-PAGE having a 4\% stacking gel and 10\% resolving gel (prepared according to the method of Laemmli [17]). The analysis was run for $55 \mathrm{~min}$ at a constant current of $25 \mathrm{~mA}$ in an Atto Dual Mini-slab Size Electrophoresis Systems AE-6450 (Atto Corporation, Tokyo, Japan). The gel was stained with Coomassie Brilliant Blue R250 and de-stained using a mixture of isopropanol, acetic acid and distilled water (12:10:78, v/v/v). The molecular weight markers (Sigma, Dublin, Ireland) contained a lyophilized mixture of proteins with molecular weight ranging from 30,000 to 200,000 Da.

\subsubsection{Amino acids analysis}

The amino acid analysis was performed in the Service of Protein Chemistry at the Centro de Investigaciones Biologicas (CSIC, Madrid) following the method described by Khiari et al. [16]. A known amount of gelatin sample was hydrolysed with $6 \mathrm{M} \mathrm{HCl}$ containing $0.1 \%$ phenol for $24 \mathrm{~h}$ at $110^{\circ} \mathrm{C}$ in vacuum-sealed hydrolysis 
vials. Norleucine (Sigma-Aldrich, Inc., Madrid, Spain) was incorporated as an internal standard. The amino acid composition was analysed by a cation exchange Biochrom 20 amino acid analyzer (Pharmacia Biotech, Ltd., Cambridge, England) using a postcolumn derivatisation technique with ninhydrin. All amino acids were determined at an absorbance of $570 \mathrm{~nm}$, except for proline and hydroxyproline which were measured at $440 \mathrm{~nm}$. Cysteine was determined as cysteic acid according to the method of Hirs [18]. Results were presented as Mole \% (i.e. residues per 100 residues).

\subsection{Solubility}

The solubility of bovine and mackerel skin gelatin was measured in the $\mathrm{pH}$ range of $2-12$ according to the method described by Khiari et al. [16]. Briefly, gelatin solutions were first prepared in distilled water to a protein concentration of $0.3 \%(\mathrm{w} / \mathrm{v})$. The $\mathrm{pH}$ of $8 \mathrm{~mL}$ gelatin solution was then adjusted to the desired $\mathrm{pH}$ value using either $1 \mathrm{M} \mathrm{HCl}$ or $1 \mathrm{M} \mathrm{NaOH}$ (Orion pH meter Model 420A, Orion Research Inc, Beverly, MA. USA). The final volume was adjusted to $10 \mathrm{~mL}$ by adding distilled water having same $\mathrm{pH}$ as the sample. Gelatin solutions were centrifuged at $9,000 \times \mathrm{g}$ for $15 \mathrm{~min}$ at $5{ }^{\circ} \mathrm{C}$ (SIGMA $2 \mathrm{~K} 15$ centrifuge, SIGMA Laborzentrifugen GmbH, Osterode, Germany). The protein content of the sample before and after centrifugation was determined using the Biuret assay [19] and considering bovine serum albumin (BSA, Sigma-Aldrich, Inc.) as a reference protein. The solubility was calculated as follows:

$$
\text { Solubility }(\%)=\frac{\text { Protein content in the supernatnat after centrifugation }}{\text { Protein content in the sample before centrifugation }}
$$




\subsection{Rheological characterisation}

A preliminary stress amplitude sweep test was performed to determine the linear viscoelastic range (LVE). The LVE is defined as the domain below a strain threshold value where the sample structure is preserved and the elastic $\left(G^{\prime}\right)$ and viscous $\left(G^{\prime \prime}\right)$ moduli show a constant high plateau (region insensitive to strain changes). Once the amplitude of the deformation exceeds the threshold value, the structure of the sample is irreversibly destroyed [20].

\subsubsection{Dynamic viscoelastic behaviour (DVB)}

The dynamic viscoelastic behaviour (DVB) of gelatin samples was performed according to the method described by Khiari et al. [21]. A controlled stress rheometer (Bohlin C-VOR, Malvern Instruments Ltd., Malvern, UK) was set to perform small oscillation with a stress of $1.0 \mathrm{~Pa}$ and a frequency of $1 \mathrm{~Hz}$, using a $5.5 \mathrm{~cm}$ parallel plate geometry with a gap of $0.2 \mathrm{~mm}$. The viscoelastic properties of gelatin solutions $(0.4 \mathrm{~mL} ; 6.67 \%, \mathrm{w} / \mathrm{v})$ were measured in the temperature range of $30-5{ }^{\circ} \mathrm{C}$ and $5-$

$30{ }^{\circ} \mathrm{C}$, with a heating/cooling rate at $1{ }^{\circ} \mathrm{C} / \mathrm{min}$. After completing the cooling process, gelatins were kept at $5{ }^{\circ} \mathrm{C}$ for 10 min before starting the heating process. The elastic modulus $\left(G^{\prime}\right)$, viscous modulus $\left(G^{\prime \prime}\right)$ and $\operatorname{Tan} \delta\left(G^{\prime \prime} / G^{\prime}\right)$ values were obtained as a function of temperature. Commercial bovine hide gelatin (Gelatin powder 104078, Merck Chemicals Ltd. Nottingham, UK) was used, at the same concentration as the extracted fish skin gelatin samples, for comparison purposes.

\subsubsection{Frequency sweep}

The frequency sweep test was performed according to the method described by Khiari et al. [21]. Gelatin (0.4 mL; 6.67\%, w/v) was placed in the lower plate of a 
Bohlin C-VOR rheometer (Malvern Instruments Ltd., Malvern, UK) and kept at $5{ }^{\circ} \mathrm{C}$ for 10 min before starting the analysis. The assay was performed using $5.5 \mathrm{~cm}$ parallel plate measuring geometry and $0.2 \mathrm{~mm}$ as a gap. The elastic modulus $\left(G^{\prime}\right)$ was obtained as a function of frequency (varying from 0.2 to $5.2 \mathrm{~Hz}$ ). Commercial bovine hide gelatin was used, at the same concentration as the extracted fish skin gelatin samples, for comparison purposes.

\subsection{Textural properties}

\subsubsection{Gel strength}

The gel strength was determined according to the AOAC method number 948.21 [10]. Gelatin solutions (6.67\%, w/v) were prepared in distilled water (at $60{ }^{\circ} \mathrm{C}$ ) then matured at $10^{\circ} \mathrm{C}$ for $16-18 \mathrm{~h}$ to form the gel. The strength of gelatin gels was

determined using an Instron Universal Testing Machine model 3300 (Instron Ltd., High Wycombe, England) fitted with a static load cell of $500 \mathrm{~N}$ and equipped with a flat-faced cylindrical probe (diameter of $1.27 \mathrm{~cm}$ ). The test was run at a penetration speed of $1 \mathrm{~mm} / \mathrm{s}$. Gel strength was expressed as the maximum force (g) obtained at $4 \mathrm{~mm}$ penetration depth on the gelatin gels. Commercial bovine hide gelatin was used, at the same concentration as the extracted fish skin gelatin samples, for comparison purposes.

\subsubsection{Cryo-scanning electron microscopy (Cryo-SEM)}

Cryo-scanning electron microscopy (Cryo-SEM) was used to observe the effects of the pre-treatment on the microstructure of the extracted gelatin gels. CryoSEM analysis was performed according to the method described by Khiari et al. [21] with minor modifications. 
Gelatin gel samples $(6.67 \%$, w/v) were first frozen by immersion in Slush Nitrogen $\left(-210^{\circ} \mathrm{C}\right)$. Samples were then fractured, warmed (at $-94.5^{\circ} \mathrm{C}, 10^{-5}$ Torr vacuum, for 15 min to sublime the water), gold coated and viewed in the cold-stage scanning electron microscopy (JEOL JSM-5410, Tokyo, Japan) at an acceleration voltage of $15 \mathrm{kV}$. Commercial bovine gelatin was used, at the same concentration as the extracted fish skin gelatin samples, for comparison purposes.

\subsection{Statistical analyses}

The whole experiment was repeated three times for three different independent batches. All the analytical analyses were performed in triplicated, except for the amino acid analysis which was performed in duplicate. Analysis of variance (ANOVA) was used to find differences between treatments. Means were compared by the least significant difference (LSD) test, at a significance level of $\mathrm{p}<0.05$ using the PROC MIXED procedure of SAS (v. 9.1.3, SAS Institute Inc., Cary, NC).

\section{Results and discussion}

\subsection{Characterisation of mackerel skin}

The average weight of the whole mackerel used in this study was $277.0 \mathrm{~g}$. Average weight of $326 \mathrm{~g}$ was reported by Toppe et al. [22] for Atlantic mackerel (Scomber scombrus). The distribution of different components of mackerel was as follows: heads constituted 16.6\%; bones, fins and tails constituted $8.5 \%$; skins constituted 17.0\%; and viscera constituted $17.0 \%$ of the whole mackerel. According to Leu et al. [23], the average edible portion of mackerel is about $53.5 \%(\mathrm{w} / \mathrm{w})$, the rest constituted the inedible parts (heads $17.1 \%$; bones, fins and tails $8.4 \%$; skins 10.3\%; and viscera 10.9\%). 
In this research study, a significant amount of waste was obtained (52.2\%). This waste was mainly constituted by skins (32.6\%), heads (31.8\%), viscera (20.1\%) and bones (16.3\%). Since skin constituted the most abundant waste from mackerel processing, it was chosen for further investigation.

The proximate composition indicated that mackerel skin comprised $64.6 \%$ water, $2.3 \%$ ash, $18.6 \%$ protein and $13.7 \%$ fat. The hydroxyproline content of mackerel skin (on a dry weight basis) was found to be $3.5 \%$ which corresponded to 24.8\% collagen content. Fish waste are typically discarded overboard or dumped to landfill. However, the European Directive 1999/31/EC on the landfill of waste [24] forbids and restricts the disposal of untreated organic waste not untended for human consumption. The development of new sustainable processes for optimal use of fish waste may represent a new approach to lower the disposal cost and increase profit. Hence, the abundant low quality collagen ( 25\%) in mackerel skins can be converted into potential value added products such as gelatin.

\subsection{Effect of organic acid concentration on the yield of gelatin extraction}

Figure 1 shows the effect of the organic acid concentration (25, 50 and 100 $\mathrm{mM}$ ) on the extraction yield (expressed on a dry basis as amount of gelatin per total amount of collagen in raw material [14]).

For all organic acid used in the present study (acetic, citric, lactic, malic and tartaric), the extraction yield was found to be significantly higher when using a concentration of $50 \mathrm{mM}$ compared to either 25 or $100 \mathrm{mM}$. At $50 \mathrm{mM}$, the extraction yield varied between $29.6 \%$ and $31.8 \%$, but no significant differences were observed among the various treatments. 
Regardless of the organic acid, the extraction yields obtained with concentrations of 25 and $100 \mathrm{mM}$ ranged between $13.1-22.5 \%$ and $13.8-21.3 \%$, respectively. It is known that the acid pre-treatment in gelatin preparation results in the swelling of the skin and the removal of non-collagenous proteins (i.e. sarcoplasmic and myofibrillar proteins) [25]. The low extraction yield at lower concentration (i.e. $25 \mathrm{mM}$ ) may therefore be due to incomplete swelling of collagen fibers and limited cleavage of collagen cross-links. On the other hand, the reduced extraction yield at higher concentration (i.e. $100 \mathrm{mM}$ ) could be due to greater solubilisation collagen and consequently greater loss during the pre-treatment step. This may be due to the fact that higher concentration of acid increases the amount of hydrogen ions and leads to the cleavage of cross-links and enhanced solubilisation of collagen [26].

\subsection{Characterisation of extracted gelatins}

\subsubsection{Proximate analysis and gelatin extraction yield}

The proximate composition and the extraction yield of mackerel skin gelatins are presented in Table 1. High protein contents (> $85 \%$ ) were observed in all gelatins regardless of the organic acid used. All mackerel skin gelatins had low moisture content and both ash and lipid contents were less than 1\%. The low fat and ash contents of the extracted gelatins may indicate the efficacy of the pre-treatment operations in eliminating fat and other impurities from mackerel skins. No significant differences were observed among the moisture, ash, protein and fat content of all the extracted mackerel skin gelatins which indicate that the organic acid did not affect the chemical composition of the extracted ingredients. 
Bovine hide gelatin had similar moisture and protein contents as the extracted fish gelatins. However, significant differences were observed between the ash and the fat contents (Table 1). The use of a mixture of strong acid cation and base anion exchangers for the deionization of mackerel fish gelatins may have resulted in low ash content $(0.7-1.0 \%)$ in these gelatins. Unlike bovine gelatin, residual fat $(0.7-0.9 \%)$ was present in the extracted gelatin. Since mackerel is a fatty fish, it would be recommended to pre-treat the skins with dilute organic solvents, such as butyl alcohol [27], in order to remove fat and obtain fat-free gelatins.

\subsubsection{Protein patterns of mackerel skin gelatin}

The protein patterns in gelatin samples were examined using SDS-PAGE (Figure 2). Both gelatins obtained from mackerel skins after pre-treatment with acetic, citric and malic acids and bovine hide gelatin comprised one $\beta$ chain and two different $\alpha_{1}$ and $\alpha_{2}$ chains (Figure 2, Lane 2, 3, 4 and 7, respectively). These chains are characteristic of type I gelatins [28]. Similar protein patterns were observed for other fish species such as megrim (Lepidorhombus boscii), Dover sole (Solea vulgaris), cod (Gadus morhua), hake (Merluccius merluccius) [29], cuttlefish (Sepia lycidas) [30] and Nile perch (Lates niloticus) [1].

Lactic and tartaric acids, on the other hand, resulted in gelatins with less $\beta$ chain but greater $\alpha$-chains as observed by their higher intensities (Figure 2, Lane 5 and 6, respectively). This may be due to the dissociation of the dimeric $\beta$ chain into monomeric $\alpha_{1}$ and $\alpha_{2}$ chains. In addition, low molecular size peptides were also observed for these gelatins. The organic acids used in the pre-treatment step hydrolyze some of crosslinks causing the loss of rigidity and insolubility of the collagen fibrils [31]. The hydroxyl groups in tartaric and lactic acid (two and one alcohol group, 
respectively) may have exhibited lyotropic properties which subsequently improved the dissociation of these two organic acids upon collagen molecules [31] and led to an enhanced degradation of collagen chains. The dissociation of $\beta$ chain and the presence of low molecular weight components in mackerel skin gelatins pre-treated with lactic and tartaric acids are an indication of their lower molecular weight distributions. According to Muyonga et al. [1], the presence of low molecular weight fragments in gelatin are associated with inferior viscoelastic properties and lower gel strength.

\subsubsection{Amino acid composition}

The amino acid composition (expressed as Mole \%) of commercial bovine hide gelatin and the extracted mackerel skin gelatins, is presented in Table 2. Minor differences were observed between mackerel skin gelatins. Glycine, the main amino acid in collagen, was present at high content (34.1 - 36.0 Mole \%). Regardless of the organic acid used in the pre-treatment, alanine, proline and hydroxyproline were relatively high in all gelatins. The imino acid contents (proline + hydroxyproline) of mackerel skin gelatins varied depending on the organic acid used in the pre-treatment step. Acetic acid pre-treatment of mackerel skins resulted in gelatin with greater proline and hydroxyproline content (16.9 Mole \%), followed by gelatins extracted after pre-treatment with citric and malic (16.8 and 15.9 Mole \%, respectively). Tartaric and lactic acid pre-treatment of mackerel skins generated gelatins with the lowest imino acids contents (15.4 Mole \%). Bovine gelatin showed lower asparagine/aspartic acid, threonine, serine and methionine contents (3.7, 1.5, 2.1 and 0.7 Mole \%, respectively) but higher valine, isoleucine, histidine, proline and hydroxyporline contents (2.3, 1.3, 0.9, 13.3 and 9.7 Mole \%, respectively) compared to all mackerel skin gelatins (Table 2) which can be mainly attributed to the intrinsic 
differences between the raw materials. It is known that gelatin does not contain tryptophan while cysteine is absent in type I gelatin [32]. Tryptophan was not present in mackerel and bovine skin gelatins. However, low contents in cysteine (0.6-1.2 Mole \%) were observed in all extracted gelatins. According to Sukkwai et al. [25], the acid pre-treatment in gelatin preparation results in swelling of the raw material and the removal of non-collagenous proteins, mainly sarcoplasmic and myofibrillar proteins. The presence of cysteine in type I gelatin may indicate a possible contamination by non-collagenous proteins during the extraction process [33]. Protein contamination might be the result of insufficient removal of these proteins by the organic acid. The degree of protein contamination can give an idea about the purity of gelatins and may therefore explain the difference among the imino acid contents. In fact, a strong significant negative correlation was observed between the imino acids and cysteine contents $(\mathrm{R}=-0.96 ; \mathrm{P}=0.01)$ indicating that the reduced amounts of proline and hydroxyproline was compensated with greater cysteine content. The differences among the imino acid contents of mackerel skin gelatins may affect their rheological properties. Hydroxyproline is known to stabilise the triple-helix strands of collagen. The hydroxyl groups in hydroxyproline are usually involved in this process by forming hydrogen bonds [34].

The nature of the organic acid (i.e. mono, di or tri-carboxylic) plays an important role in the swelling (i.e. uptake of water) of collagen fibres. In acid solutions, the swelling of fibrous proteins, such as collagen, is due to the osmotic pressure arising from the salt formation between the free amino groups of collagen molecules and the organic acid through the Donnan effect [35]. It is known that citric acid is more efficient than tartaric acid in terms of swelling capacity of fish skin [36]. In addition, the swelling of fish skin collagen by lactic acid has been found to be three 
times greater than that produced by acetic and tartaric acid [36]. The strength of the organic acid may also have resulted in the differences observed among the amino acid content of mackerel skin gelatins. Among all the organic acid used in this study, acetic acid had the lowest pKa value $\left(4.76\right.$ at $\left.25^{\circ} \mathrm{C}\right)$. According to Bowes and Kenten [37] at $\mathrm{pH} 3$ or lower, the weaker the acid the greater the swelling is. Hence, the use of acetic acid in the pre-treatment may have favoured the disruption of collagen crosslinks and resulted in efficient extraction of gelatin.

\subsection{Gelatin solubility}

The protein solubility is an important functional property which provides a prediction of the potential application of proteins. The solubility of mackerel skin gelatin and commercial bovine hide gelatin was measured in the $\mathrm{pH}$ range of 2 to 12 and is depicted in Figure 3.

All mackerel skin gelatins, regardless of the pre-treatment, showed similar $\mathrm{pH}$ behaviours. The solubility was higher at low and high $\mathrm{pH}$ values, with maximum at alkaline $\mathrm{pH}$ values. Commercial bovine gelatin had better solubility than mackerel gelatin with highest solubility value obtained at $\mathrm{pH}$ 2. For both fish and bovine gelatins, the least solubility was observed close to neutral $\mathrm{pH}$. Similar solubility results were reported for bigeye snapper skin collagen [38]. The differences in solubility between mackerel and bovine gelatins might be due to the differences in amino acid compositions mainly the content of polar and non-polar groups in amino acids.

\subsection{Rheological properties of extracted gelatins}

\subsubsection{Dynamic viscoelastic behaviour}


Figure 4 shows the viscoelastic properties, including the storage and loss moduli as well as the phase angle during the cooling (Figure 4 A, C \& E) and heating ramps (Figure 4 B, D \& F) of commercial bovine gelatin and mackerel skin gelatins extracted after pre-treatment with acetic, citric, lactic, malic and tartaric acids.

In the cooling ramp (i.e. from $30{ }^{\circ} \mathrm{C}$ to $5{ }^{\circ} \mathrm{C}$ ), the elastic modulus $\left(G^{\prime}\right)$ of all mackerel skin gelatins increased rapidly between 17 and $10{ }^{\circ} \mathrm{C}$, representing the transition from solution to gel state (Figure 4 A). Slight differences on the increase rate were observed. Similar behaviour was observed for the viscous modulus $\left(G^{\prime \prime}\right)$ with a gradual increase (Figure $4 \mathrm{C}$ ).

As observed from the heating ramp (i.e. from $5{ }^{\circ} \mathrm{C}$ to $30{ }^{\circ} \mathrm{C}$ ), the elastic modulus $\left(G^{\prime}\right)$ of all mackerel skin gelatins decreased slowly between 5 and $15^{\circ} \mathrm{C}$ then a rapid decrease was observed between $15{ }^{\circ} \mathrm{C}$ and $23{ }^{\circ} \mathrm{C}$ representing the transition from gel to solution (Figure $4 \mathrm{~B}$ ). The differences among the values of $G^{\prime}$ at $5{ }^{\circ} \mathrm{C}$ during the cooling and heating process could due to the maturation of gelatins at $5{ }^{\circ} \mathrm{C}$ for 10 minutes before starting the heating process. The viscous modulus $\left(G^{\prime \prime}\right)$, showed similar behaviour, with the exception that the decrease was gradual (Figure 4 D).

In both processes (cooling and heating) the phase angle showed similar profiles. All mackerel skin gelatins had a low phase angle at low temperature (Figure 4 E \& F) which indicates good gelling ability [39]. The slight differences in the transition curves during the melting and gelling processes among gelatins resulted in slight differences in gelling and melting temperatures of these gelatins. In this study, the gelling temperatures varied from $11.8{ }^{\circ} \mathrm{C}$ and $12.9{ }^{\circ} \mathrm{C}$, while the melting temperatures ranged from $18.4{ }^{\circ} \mathrm{C}$ and $20.4{ }^{\circ} \mathrm{C}$. Previous studies showed that the melting temperatures for fish gelatins vary from $15{ }^{\circ} \mathrm{C}$ to $32{ }^{\circ} \mathrm{C}$ [40-42]. The melting temperatures in the present study were lower than that of common mackerel $\left(26.1^{\circ} \mathrm{C}\right)$ 
as reported by Kimura et al. [42]. This could be due to the variation among the species, the temperature of the habitat, the extraction procedure, the $\mathrm{pH}$ and the concentration of gelatins [40].

The amino acid result (Table 2) indicated that mackerel skin gelatins extracted after pre-treatment with acetic acid had the highest imino acid (proline and hydroxyproline) content, followed by gelatins extracted after pre-treatment with citric, malic, tartaric and lactic acid. These differences may explain the slight difference in gelling and melting temperatures of these gelatins. Commercial bovine hide gelatin had higher viscoelastic properties (i.e. greater elastic and viscous moduli) than all the extracted mackerel skin gelatins (Figure 4), which resulted in considerably higher gelling and melting points $\left(18{ }^{\circ} \mathrm{C}\right.$ and $27^{\circ} \mathrm{C}$, respectively) compared to the extracted fish gelatins. The better viscoelastic properties of bovine skin gelatin compared to mackerel skin gelatins may be due to the difference in proline and hydroxyproline contents (Table 2). According to Gilsenan \& Ross-Murphy [43] the poor rheological properties of fish gelatins compared to mammalian gelatins may be attributed to the difference in imino acid content. It was also suggested that gelatins with higher imino acid content have better rheological properties with higher ability to regain triple helix structures leading to stabilisation of gelatin gels [29].

\subsubsection{Frequency sweep analyses}

The effect of the frequency on the elastic $\left(G^{\prime}\right)$ modulus was studied (Figure 5). These analyses were carried out to verify the rheological behaviour of the gelatins and to assess the strength of the gel network. For all mackerel skin gelatin samples, a slight dependence of $G^{\prime}$ values on the frequency was observed. These results were similar to those observed for cod gelatins [43]. The slopes of $G^{\prime}$ values as a function 
of frequency varied slightly among the gelatins depending on the organic acids used. All gelatins gels from mackerel skins showed relatively good textural stability as proven by the low slope of regression lines for $G^{\prime}$ versus frequency (varying from 0.3 to 0.6 ). Low slope is an indication of good gel networks and better stability of gelatin gels when subjected to shear forces [44].

Commercial bovine hide gelatin gel, on the other hand, was very stable, less affected by the change in frequency and stronger than all mackerel skin gelatin gels (Figure 5).

\subsection{Textural and microstructural properties of extracted gelatins}

\subsubsection{Gel strength}

Gel strength is one of the most important physical properties of gelatin [45]. The gel strength of the various gelatin preparations, after overnight maturation at 10 ${ }^{\circ} \mathrm{C}$, is presented in Table 1 .

The gel strength of mackerel skin gelatins was affected by the organic acid. Gelatins extracted from mackerel skins after pre-treatment with acetic, citric and malic showed significantly $(\mathrm{p}<0.05)$ high gel strength $(71.1-80.2$ g) corresponding with gelatin having the highest imino acid contents. As previously discussed (Table 2), tartaric and lactic acid pre-treated gelatins had the least proline and hydrolxyproline levels (15.4 Mole \%), which resulted in lower gel strength (49.4 and $43.3 \mathrm{~g}$, respectively). Gelatins with a bloom value of $108 \mathrm{~g}$ for salmon and $71 \mathrm{~g}$ for cod skins were reported by Arnesen and Gildberg [3]. Commercial bovine hide gelatin had significantly greater gel strength (244.7 g) compared to all mackerel skin gelatins which could be due to its higher content of imino acids. It is known that the low hydroxyproline content in fish gelatin is responsible for the low gel strength [46]. 
Other factors affecting the gel strength could be the $\mathrm{pH}$ of gelatins. The gel strength might be dependent on the isoelectric point and could also be controlled by adjusting the $\mathrm{pH}$ [47]. In this study, all mackerel skin gelatins had similar solubility behaviour in the $\mathrm{pH}$ range of $2-12$ (Section 3.2). The greatest solubility percentages were observed at low and high $\mathrm{pH}$ values (Figure 3). The least solubility percentages were obtained at neutral $\mathrm{pH}$ corresponding to the isoelectric point of these gelatins.

\subsubsection{Microstructural analysis of gelatins texture by cryo-scanning electron microscopy (cryo-SEM)}

Micrographs (Cryo-SEM) of various gelatins were carried out to investigate the gel microstructure. Cryo-SEM images (Figure 6) showed that commercial bovine hide gelatin had a honeycomb structure with thin stranded protein network and large number of interconnected pores. These pores were very small and uniform (Figure 6 A). However, all extracted mackerel skin gelatins showed larger voids indicating a relatively weaker gel nature since the higher the number of small interconnected pores, the stronger the gel is [48].

Mackerel skin gelatins extracted after pre-treatment with acetic, citric and

malic acid (Figure 6 B, C \& E, respectively) showed a higher number of interconnected small pores than mackerel skin gelatins extracted after pre-treatment with tartaric and lactic acid (Figure 6 D \& F, respectively). The CryoSEM results showed that the microstructures were highly related to the gel strength values, where denser strands (gelatins extracted from mackerel skins after pre-treatment with acetic, citric and malic acid) represented higher gel strength than the looser strands such as in the case of mackerel skin gelatins pre-treated with tartaric and lactic acid. 


\section{Conclusion}

The rheological, textural and microstructural properties of mackerel skin gelatins were affected by the organic acid used in the extraction process. The differences among gelatins were related to the imino acids (proline and hydroxyproline) level of gelatins. The use of tartaric and lactic acids resulted in gels with poor rheological properties and weak network structure. Acetic, citric and malic acid pre-treatment of mackerel skins produced stronger and more stable gels making them possibly useful in various food applications.

\section{Acknowledgements}

This work was conducted with the financial support from the Irish government under FIRM 2006. The authors would like to acknowledge their support. Many thanks go to Mr. John Fagan from BIM for providing the fish and Dr. José Manuel Barat from the Universidad Politécnica de Valencia for assistance with the cryo-SEM analysis.

\section{References}

1. Muyonga JH, Cole CGB, Duodu KG (2004) Characterisation of acid soluble collagen from skins of young and adult Nile perch (Lates niloticus). Food Chem 85:81-89

2. Zhou P, Mulvaney SJ, Regenstein JM (2006) Properties of Alaska Pollock skin gelatin: a comparison with tilapia and pork skin gelatins. J Food Sci 71:313-321

3. Arnesen JA, Gildberg A (2007) Extraction and characterisation of gelatine from Atlantic salmon (Salmo salar) skin. Bioresour Technol 98:53-57 
4. Haug IJ, Draget KI, Smidsrød O (2004) Physical and rheological properties of fish gelatin compared to mammalian gelatine. Food Hydrocolloid 18:203-213

5. Gómez-Guillén MC, Ihl M, Bifani V, Silva A, Montero P (2007) Edible films made from tuna-fish gelatin with antioxidant extracts of two different murta ecotypes leaves (Ugni molinae Turcz). Food Hydrocolloid 21:1133-1143

6. FAO Statistical Yearbook (2012) World Food and Agriculture. Food Agriculture Organization of the United Nations, Rome.

7. Crapo C, Paust B, Babbitt J (1993) Recoveries and yields from Pacific fish and shellfish. Mar Advis Bull 37 Rev:1-37

8. Kim SK, Mendis E (2006) Bioactive compounds from marine processing byproducts - A review. Food Res Int 39:383-393

9. Montero P, Gómez-Guillén MC (2000) Extracting conditions for megrim (Lepidorhombus boscii) skin collagen affect functional properties of the resulting gelatine. J Food Sci 65:434-438

10. Method 927.05, Method 942.05, Method 984.13, Method 948.21. In: Horwitz W (ed) Official Methods of Analysis of AOAC International. Association of Official Analytical Chemists International, Gaithersburg, Maryland (2000)

11. Bligh EG, Dyer WJ (1959) A rapid method for total lipid extraction and purification. Can. J. Biochem. Phys. 37:911-917

12. Edwards CA, O'Brien WD Jr (1980) Modified assay for determination of hydroxyproline in a tissue hydrolyzate. Clin Chim Acta 104:161-167

13. Khiari Z, Rico D, Martin-Diana AB, Barry-Ryan C (2011) The extraction of gelatine from Mackerel (Scomber scombrus) heads with the use of different organic acids. J FisheriesSciences.com 5:52-63

14. Du L, Khiari Z, Pietrasik Z, Betti M (2013) Physico-chemical and functional properties of gelatins extracted from turkey and chicken heads. Poult Sci 92:2463-2474 
15. Eastoe JE, Eastoe B (1952) A method for the determination of total nitrogen in proteins. The British Gelatine and Glue Research Association Research Report, Series B 5:1-17

16. Khiari Z, Rico D, Martin-Diana AB, Barry-Ryan C (2013) Comparison between gelatines extracted from mackerel and blue whiting bones after different pre-treatments. Food Chem 139:347-354

17. Laemmli UK (1970) Cleavage of structural proteins during the assembly of the head of bacteriophage T4. Nature 227:680-685

18. Hirs CHW (1967) Determination of cystine as cysteic acid. Methods Enzymol 11:59-62.

19. Gornall AG, Bardawill CJ, David MM (1949) Determination of serum proteins by means of the biuret reaction. J Biol Chem 177:751-766

20. Di Giuseppe E, Funiciello F, Corbi F, Ranalli G, Mojoli G (2009) Gelatins as rock analogs: A systematic study of their rheological and physical properties. Tectonophysic 473:391-403

21. Khiari Z, Rico D, Martin-Diana AB, Barry-Ryan C (2014) Characterisation of blue whiting skin gelatines extracted after pre-treatment with different organic acids. J Aquat Food Prod Technol. doi:10.1080/10498850.2013.791904

22. Toppe J, Albrektsen S, Hope B, Aksnes A (2007) Chemical composition, mineral content and amino acid and lipid profiles in bones from various fish species. Comp Biochem Physiol Part B: Biochem Mol Biol 146:395-401

23. Leu SS, Jhaveri SN, Karakoltsidis PA, Constantinides SM (1981) Atlantic mackerel (Scomber scombrus): seasonal variation in proximate composition and distribution of chemical nutrients. J Food Sci 46:1635-1638

24. Council Directive 1999/31/EC of 26 April 1999 on the landfill of waste. Off J Eur Comm L 182, 16/07/1999 
25. Sukkwai S, Kijroongrojana K, Benjakul S (2011) Extraction of gelatin from bigeye snapper (Priacanthus tayenus) skin for gelatin hydrolysate production. Int Food Res J 18: 1129-1134

26. Giménez B, Turnay J, Lizarbe MA, Montero P, Gómez-Guillén MC (2005) Use of Lactic Acid for Extraction of Fish Skin Gelatin. Food Hydrocolloid 19:941-950

27. Nagai T, Suzuki N (2000) Isolation of collagen from fish waste material-skin, bone and fins. Food Chem 68:277-281

28. Gómez-Guillén MC, Montero P (2001) Extraction of gelatine from megrim (Lepidorhombus boscii) skins with several organic acids. J Food Sci 66:213216

29. Gómez-Guillén MC, Turnay J, Fernandez-Diaz MD, Ulmo N, Lizarbe MA, Montero P (2002) Structural and physical properties of gelatin extracted from different marine species: a comparative study. Food Hydrocolloid 16:25-34

30. Nagai T, Yamashita E, Taniguchi K, Kanamori N, Suzuki N (2001) Isolation and characterisation of collagen from the outer skin waste material of cuttlefish (Sepia lycidas). Food Chem 72:425-429

31. Bellon G, Wegrowski J, Perreau C, Randoux A, Borel JP, Malgras A, Chastang F (1988) A parallel between two techniques of extraction of connective tissue macromolecules. Anal Biochem 175:263-73

32. Schrieber R, Gareis H (2007) Gelatine Handbook: Theory and industrial practice. Wiley-VCH GmbH \& Co., Weinhem, Germany

33. Morimura S, Nagata H, Uemura Y, Fahmi A, Shigematsu T, Kida K (2002) Development of an effective process for utilization of collagen from livestock and fish waste. Process Biochem 37:1403-1412 
34. Ledward DA (1986) Gelation of gelatin. In: Mitchell JR, Ledward DA (ed) Functional Properties of Food Macromolecules. Elsevier Applied Science Publishers Ltd., London, pp 171-201

35. Matsuura T, Idota N, Hara Y, Annaka M (2009) Dynamic light scattering study of pig vitreous body. Progr Colloid Polym Sci 136:195-204

36. Kernot JC, Knaggs J (1929) The swelling of fish skins in solutions of inorganic and organic acids. Proc R Soc B 105:280-293

37. Bowes JH, Kenten RH (1947) Uptake of water by collagen in solutions of alkalis and strong and weak organic bases. Nature 160:827-828

38. Kittiphattanabawon P, Benjakul S, Visessanguan W, Nagai T, Tanaka M (2005) Characterisation of acid-soluble collagen from skin and bone of bigeye snapper (Priacanthus tayenus). Food Chem 89:363-372

39. Gómez-Guillén MC, Giménez B, Montero P (2005) Extraction of gelatin from fish skins by high pressure treatment. Food Hydrocolloid 19:923-928

40. Rigby BJ (1968) Amino acid composition and thermal stability of the skin collagen of the Antarctic ice-fish. Nature 219:166-167

41. Kimura S, Ohno Y (1987) Fish type I collagen: Tissue specific existence of two molecular forms, $(\alpha 1) 2 \alpha 2$ and $\alpha 1 \alpha 2 \alpha 3$ in Alaska pollack. Comp Biochem Physiol 88B:409-413

42. Kimura S, Zhu X, Matsui R, Shijoh M, Takamizawa S (1988) Characterisation of fish muscle type I collagen. J Food Sci 23:1315-1316

43. Gilsenan PM, Ross-Murphy SB (2000) Rheological characterisation of gelatins from mammalian and marine sources. Food Hydrocolloid 14:191-196

44. Binsi PK, Shamasundar BA, Dileep AO, Badii F, Howell NK (2009) Rheological and functional properties of gelatin from the skin of Bigeye 
snapper (Priacanthus hamrur) fish: Influence of gelatin on the gel-forming ability of fish mince. Food Hydrocolloid 23: 132-145

45. Cheow CS, Norizah MS, Kyaw ZY, Howell NK (2007) Preparation and characterisation of gelatins from the skins of sin croaker (Johnius dussumieri) and shortfin scad (Decapterus macrosoma). Food Chem 101:386-391

46. Arnesen JA, Gildberg A (2002) Preparation and characterisation of gelatine from the skin of harp seal (Phoca groendlandica). Bioresour Technol 82:191194

47. Gundmundsson H, Hafsteinsson H (1997) Gelatin from cod skins as affected by chemical treatments. J Food Sci 52:37-39

48. Wangtueai S, Noomhorm A (2009). Processing optimization and characterization of gelatin from lizardfish (Saurida spp.) scales. LWT - Food Sci Technol 42:825-834 


\section{Figure captions}

Fig. 1 Effect of the organic acid concentration on gelatin extraction yield

${ }^{\mathrm{a}-\mathrm{e}}$ Means sharing a common letter are not significantly different from each other, $\mathrm{P}>$ 0.05

Fig. 2 SDS-PAGE patterns of commercial bovine hide gelatin and mackerel skin gelatins extracted after pre-treatment with different organic acids

Lane 1: Molecular weight markers (M.W. 30,000-200,000 Da), lane 2: acetic acidextracted gelatin, lane 3: citric acid-extracted gelatin, lane 4: malic acid-extracted gelatin, lane 5: lactic acid-extracted gelatin, lane 6: tartaric acid-extracted gelatin, lane 7: commercial bovine hide gelatin

Fig. 3 Solubility of mackerel skin gelatins, extracted using different organic acids, in the $\mathrm{pH}$ range $2-12$

AA: acetic acid-extracted gelatin, CA: citric acid-extracted gelatin, LA: lactic acidextracted gelatin, MA: malic acid-extracted gelatin, TA: tartaric acid-extracted gelatin, Bovine: commercial bovine hide gelatin. Each point represents the average of three measurements

Fig. 4 Viscoelastic properties of commercial bovine hide gelatin and mackerel skin gelatins extracted after pre-treatment with different organic acids

Changes in the elastic modulus G' (A \& B), viscous modulus $G$ ” (C \& D) and phase angle (E \& F), were analysed during cooling from $30^{\circ} \mathrm{C}$ to $5^{\circ} \mathrm{C}(\mathrm{A}, \mathrm{C} \& \mathrm{E})$ and subsequent heating from $5{ }^{\circ} \mathrm{C}$ to $30{ }^{\circ} \mathrm{C}(\mathrm{B}, \mathrm{D} \& \mathrm{~F})$ 
AA: acetic acid-extracted gelatin, CA: citric acid-extracted gelatin, LA: lactic acidextracted gelatin, MA: malic acid-extracted gelatin, TA: tartaric acid-extracted gelatin, Bovine: commercial bovine hide gelatin. Each point represents the average of three measurements

Fig. 5 Frequency sweep test of commercial bovine hide gelatin and mackerel skin gelatins gels at $5{ }^{\circ} \mathrm{C}$

AA: acetic acid-extracted gelatin, CA: citric acid-extracted gelatin, LA: lactic acidextracted gelatin, MA: malic acid-extracted gelatin, TA: tartaric acid-extracted gelatin, Bovine: commercial bovine hide gelatin

Each point represents the average of three measurements

Fig. 6 Representative cryo-SEM micrographs $(\times 1,500)$ of gelatin gels

Commercial bovine hide gelatin (A), gelatin from mackerel skin pre-treated with acetic acid (B), citric acid (C), lactic acid (D), malic acid (E) and tartaric acid (F)

\section{Table captions}

Table 1 Proximate analysis and gel strength of commercial bovine hide gelatin and and mackerel skin gelatins extracted after pre-treatment with different organic acids

Table 2 Average amino acid composition (Moles \%) of commercial bovine hide gelatin and and mackerel skin gelatins extracted after pre-treatment with different organic acids 
Fig. 1

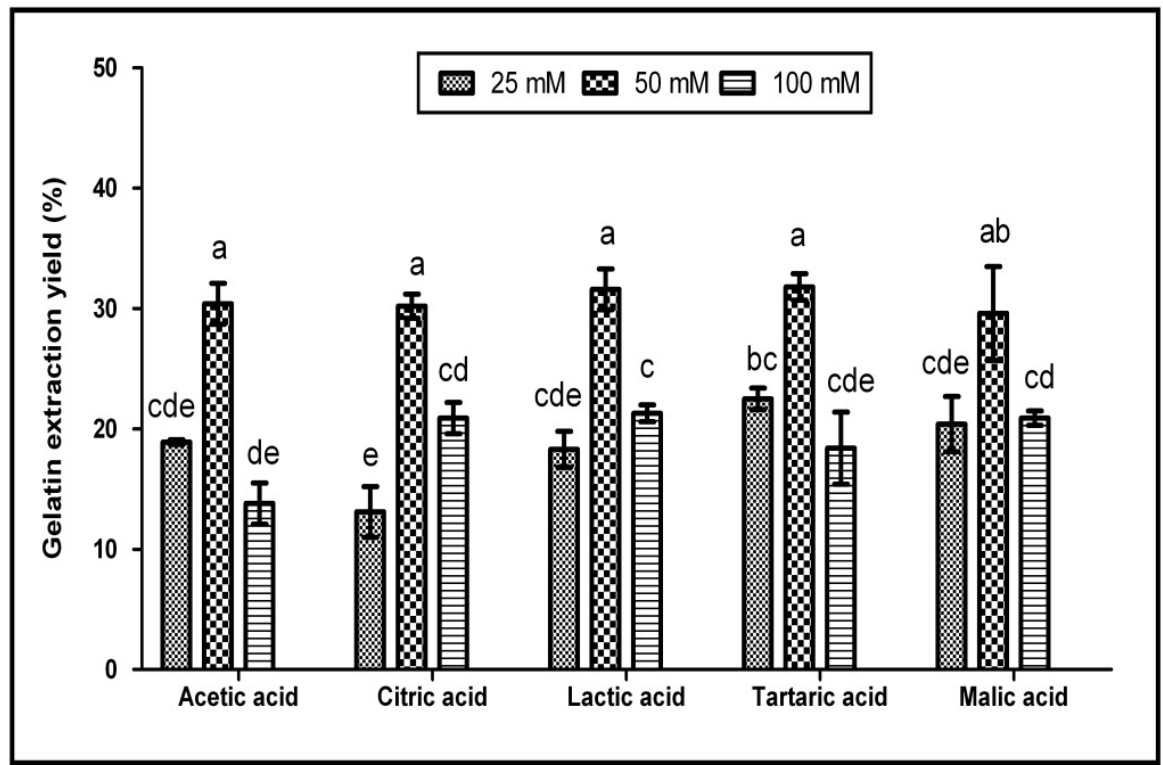


Fig. 2

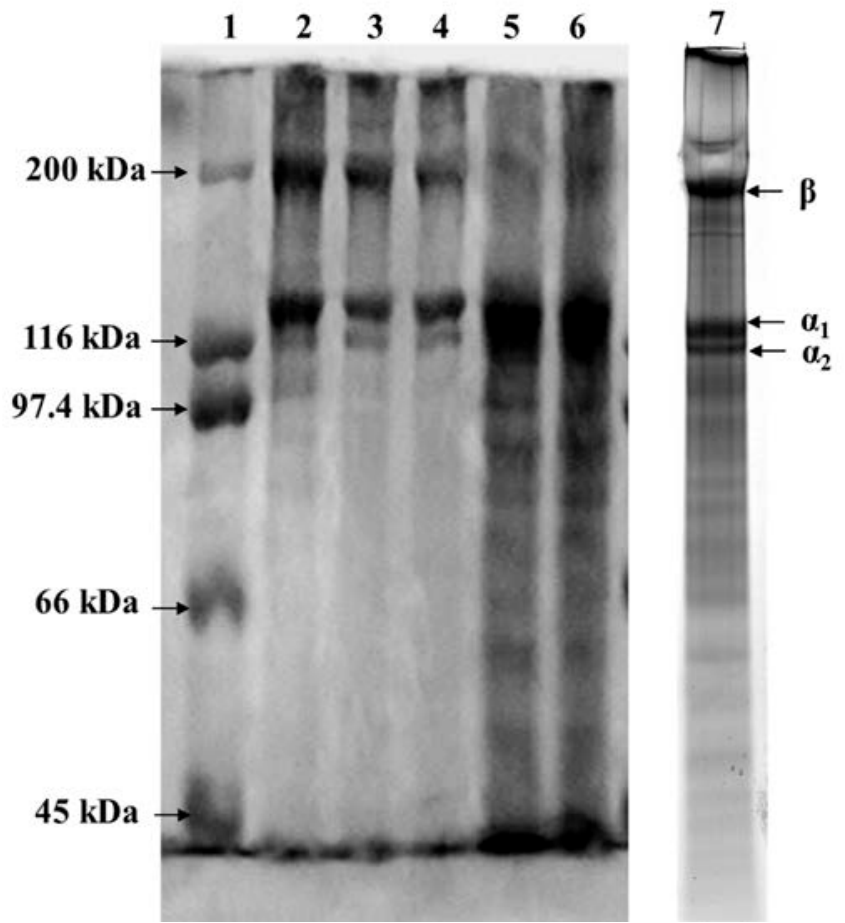


Fig. 3

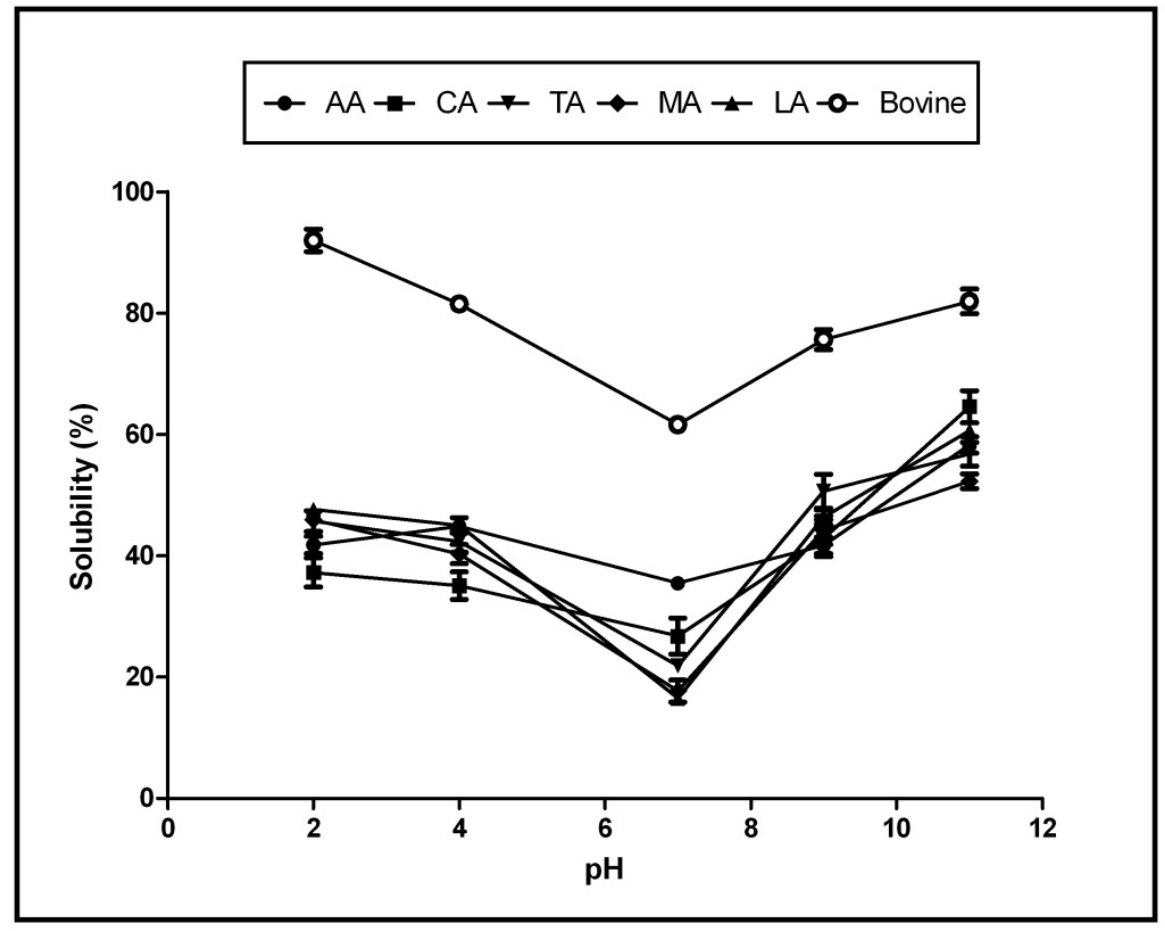


Fig. 4

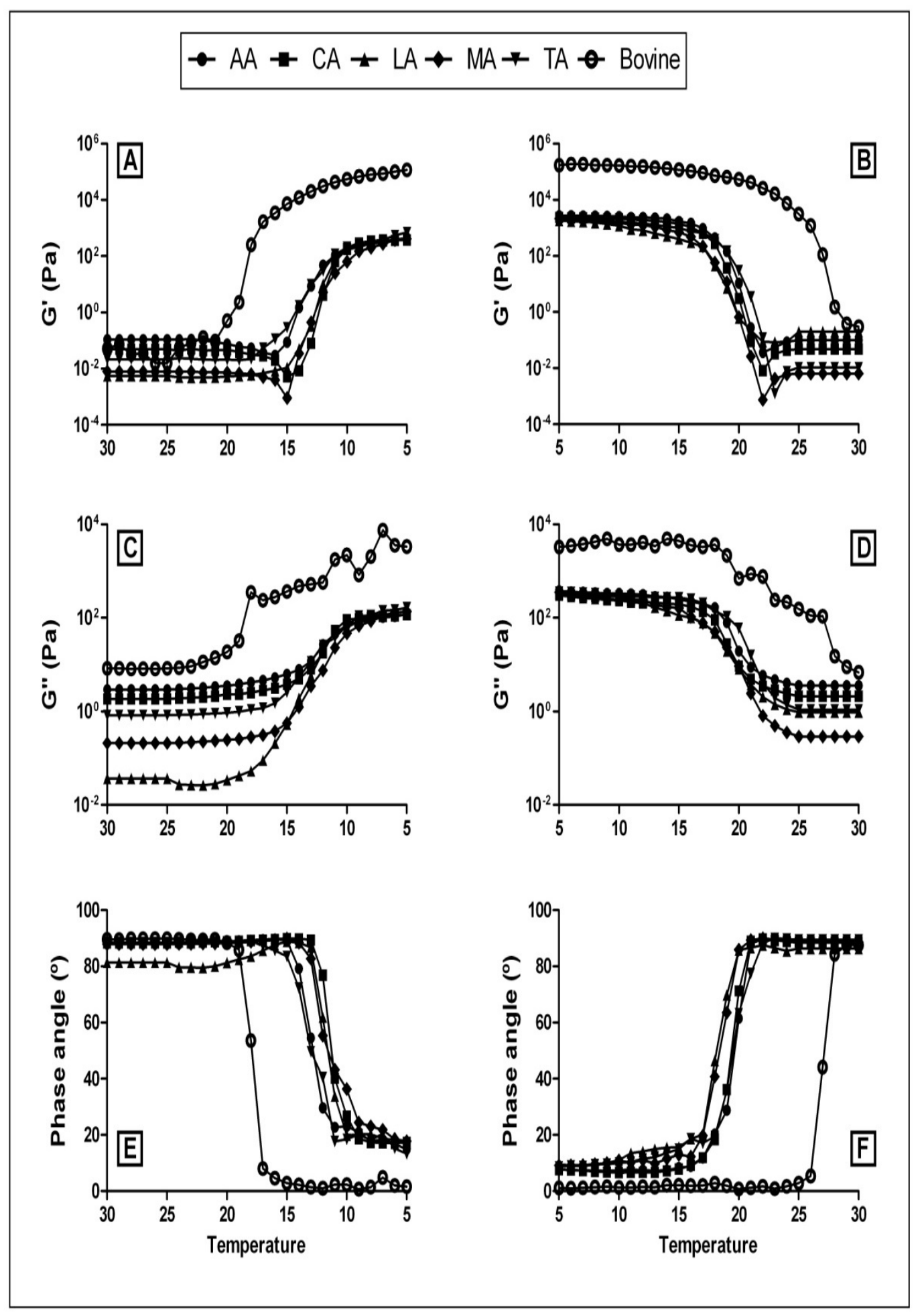


Fig. 5

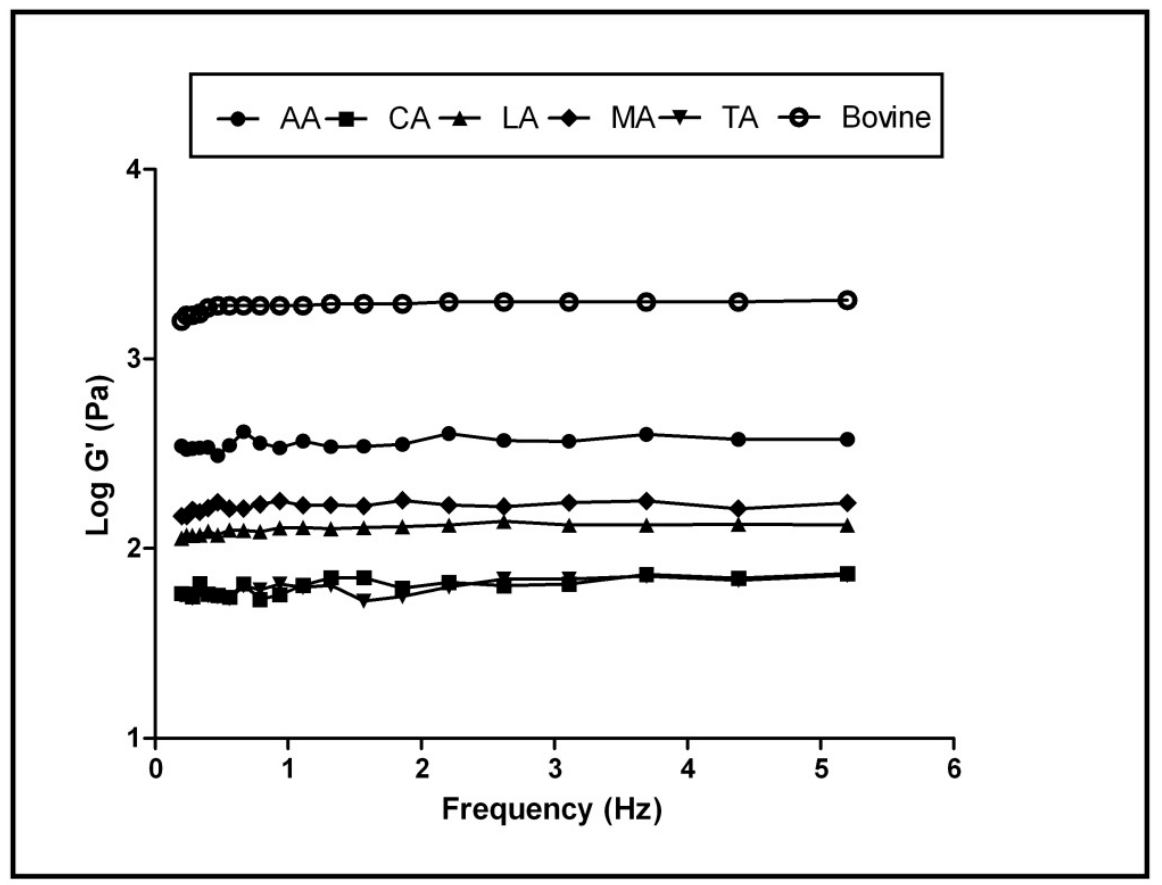


Fig. 6

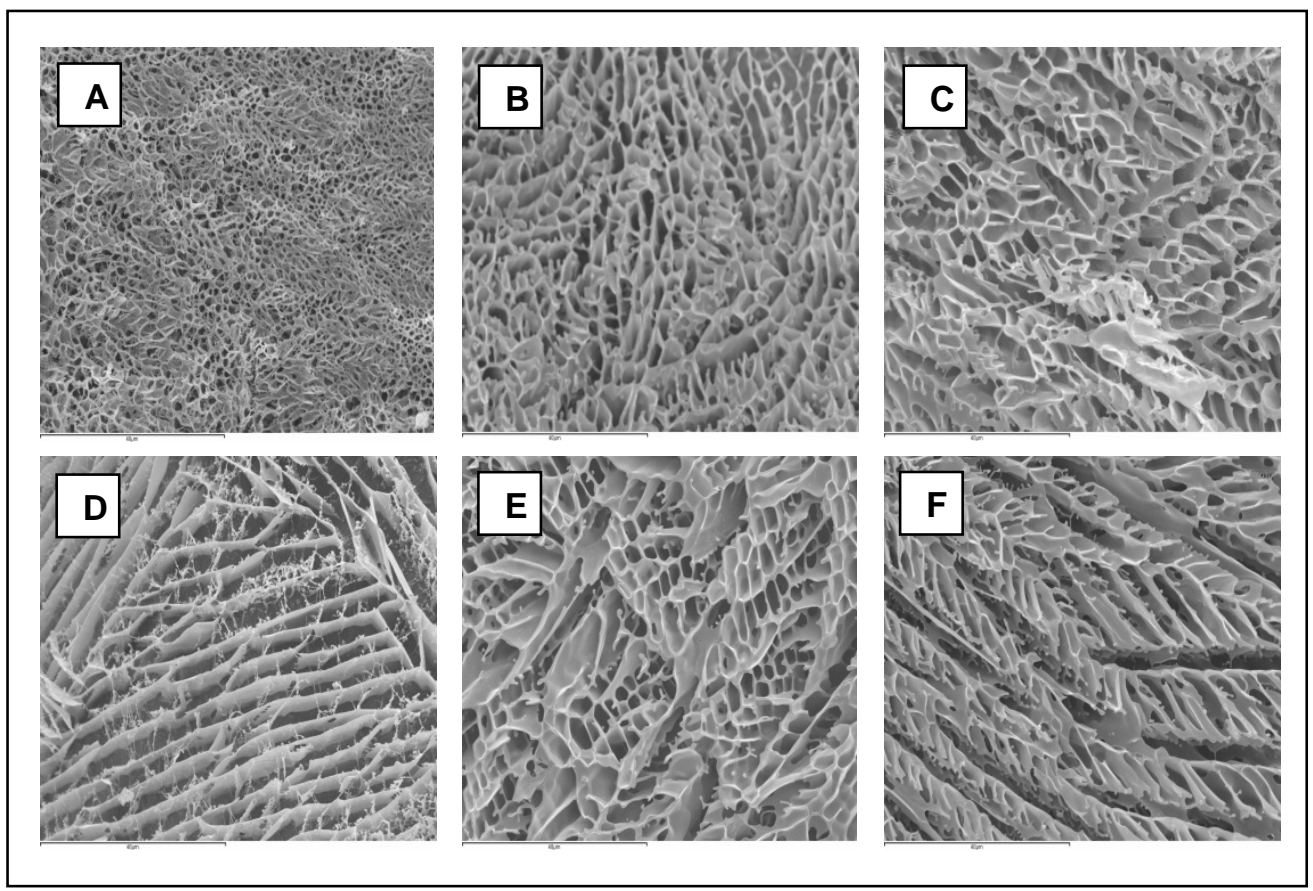


Table 1

\begin{tabular}{|c|l|c|c|c|c|c|}
\hline Gelatin & \multicolumn{1}{|c|}{$\begin{array}{c}\text { Pre- } \\
\text { treatment }\end{array}$} & $\begin{array}{c}\text { Moisture } \\
(\mathbf{\%})\end{array}$ & $\begin{array}{c}\text { Ash } \\
\mathbf{( \% )}\end{array}$ & $\begin{array}{c}\text { Protein } \\
(\mathbf{\%})\end{array}$ & $\begin{array}{c}\text { Lipid } \\
\mathbf{( \% )}\end{array}$ & $\begin{array}{c}\text { Gel strength } \\
(\mathbf{g})\end{array}$ \\
\hline & AA & $10.3 \pm 1.8$ & $0.8 \pm 0.1^{\mathrm{b}}$ & $86.2 \pm 1.3$ & $0.7 \pm 0.1^{\mathrm{a}}$ & $80.2 \pm 1.4^{\mathrm{b}}$ \\
\cline { 2 - 7 } & CA & $9.0 \pm 1.9$ & $0.7 \pm 0.2^{\mathrm{b}}$ & $87.2 \pm 2.8$ & $0.9 \pm 0.2^{\mathrm{a}}$ & $76.4 \pm 0.7^{\mathrm{b}}$ \\
\cline { 2 - 7 } Mackerel & LA & $10.2 \pm 1.7$ & $0.8 \pm 0.1^{\mathrm{b}}$ & $85.0 \pm 2.7$ & $0.7 \pm 0.2^{\mathrm{a}}$ & $43.3 \pm 0.7^{\mathrm{c}}$ \\
\cline { 2 - 7 } & MA & $8.7 \pm 1.6$ & $0.7 \pm 0.2^{\mathrm{b}}$ & $87.2 \pm 2.0$ & $0.9 \pm 0.3^{\mathrm{a}}$ & $71.1 \pm 3.6^{\mathrm{b}}$ \\
\cline { 2 - 7 } & TA & $8.9 \pm 1.2$ & $1.0 \pm 0.2^{\mathrm{b}}$ & $85.9 \pm 1.9$ & $0.8 \pm 0.1^{\mathrm{a}}$ & $49.4 \pm 1.4^{\mathrm{c}}$ \\
\hline \multirow{2}{*}{ Bovine } & - & $9.9 \pm 0.0$ & $1.5 \pm 0.1^{\mathrm{a}}$ & $88.7 \pm 0.2$ & $0.0 \pm 0.0^{\mathrm{b}}$ & $244.7 \pm 14.4^{\mathrm{a}}$ \\
\hline & P-value & 0.3502 & 0.0209 & 0.3872 & 0.0135 & $<0.0001$ \\
\hline
\end{tabular}

Values are given as mean \pm standard deviation

${ }^{\mathrm{a}-\mathrm{c}}$ Means within the same column sharing a common letter are not significantly different from each other, $\mathrm{P}>0.05$

AA: acetic acid-extracted gelatin, CA: citric acid-extracted gelatin, LA: lactic acidextracted gelatin, MA: malic acid-extracted gelatin, TA: tartaric acid-extracted gelatin 
Table 2

\begin{tabular}{|c|c|c|c|c|c|c|}
\hline \multirow{3}{*}{$\begin{array}{l}\text { Amino } \\
\text { acid }\end{array}$} & \multicolumn{6}{|c|}{ Content (Mole \%) } \\
\hline & \multicolumn{5}{|c|}{ Mackerel gelatin } & \multirow{2}{*}{$\begin{array}{l}\text { Bovine } \\
\text { gelatin }\end{array}$} \\
\hline & $\mathbf{A A}$ & CA & LA & MA & TA & \\
\hline $\operatorname{Asx}^{\mathrm{a}}$ & 4.8 & 4.8 & 5.2 & 4.9 & 4.7 & 3.7 \\
\hline Thr & 2.4 & 2.4 & 2.5 & 2.4 & 2.5 & 1.5 \\
\hline Ser & 5.0 & 5.5 & 5.4 & 5.0 & 5.4 & 2.1 \\
\hline $\mathrm{Glx}^{\mathrm{b}}$ & 7.1 & 6.9 & 6.7 & 6.7 & 7.3 & 7.0 \\
\hline Gly & 36.0 & 34.2 & 34.7 & 35.6 & 35.1 & 33.6 \\
\hline Ala & 11.6 & 11.9 & 11.9 & 11.8 & 11.8 & 11.3 \\
\hline Cys & 0.6 & 0.8 & 1.1 & 1.0 & 1.2 & 0.0 \\
\hline Trp & ND & ND & ND & ND & ND & ND \\
\hline Val & 1.6 & 1.7 & 1.9 & 1.7 & 1.8 & 2.3 \\
\hline Met & 1.4 & 1.3 & 1.4 & 1.4 & 1.3 & 0.7 \\
\hline Ile & 0.8 & 0.9 & 0.9 & 0.9 & 0.9 & 1.3 \\
\hline Leu & 2.4 & 2.5 & 2.7 & 2.6 & 2.6 & 2.6 \\
\hline Tyr & 0.4 & 0.5 & 0.5 & 0.4 & 0.5 & 0.6 \\
\hline Phe & 1.5 & 1.4 & 1.5 & 1.6 & 1.5 & 1.3 \\
\hline His & 0.4 & 0.6 & 0.6 & 0.6 & 0.5 & 0.9 \\
\hline Lys & 2.3 & 2.6 & 2.4 & 2.5 & 2.6 & 2.8 \\
\hline Arg & 4.9 & 5 & 5.1 & 5.1 & 5.1 & 5.2 \\
\hline Pro & 9.5 & 10.8 & 10.1 & 9.7 & 10 & 13.3 \\
\hline Нyp & 7.4 & 5.9 & 5.3 & 6.3 & 5.4 & 9.7 \\
\hline Total & 100.0 & 100.0 & 100.0 & 100.0 & 100.0 & 100.0 \\
\hline Pro + Hyp & 16.9 & 16.8 & 15.4 & 15.9 & 15.4 & 23.0 \\
\hline
\end{tabular}

The amino acid composition was performed in duplicate and data correspond to mean values

AA: acetic acid-extracted gelatin, CA: citric acid-extracted gelatin, LA: lactic acidextracted gelatin, MA: malic acid-extracted gelatin, TA: tartaric acid-extracted gelatin

${ }^{\text {a }}$ Represents the sum of aspartic acid (asp) and asparagine (asn)

${ }^{\mathrm{b}}$ Represents the sum of glutamic acid (glu) and glutamine (gln)

ND: not detected 